\title{
Review Article \\ The Roles of Regulatory B Cells in Cancer
}

\author{
Yan He, Hongyan Qian, Yuan Liu, Lihua Duan, Yan Li, and Guixiu Shi \\ Department of Rheumatology and Clinical Immunology, The First Affiliated Hospital of Xiamen University, Xiamen 361003, China
}

Correspondence should be addressed to Guixiu Shi; guixiu.shi@gmail.com

Received 23 February 2014; Revised 28 April 2014; Accepted 12 May 2014; Published 2 June 2014

Academic Editor: Yi Zhang

Copyright (c) 2014 Yan He et al. This is an open access article distributed under the Creative Commons Attribution License, which permits unrestricted use, distribution, and reproduction in any medium, provided the original work is properly cited.

\begin{abstract}
Regulatory B cells (Bregs), a newly described subset of B cells, have been proved to play a suppressive role in immune system. Bregs can inhibit other immune cells through cytokines secretion and antigen presentation, which give them the role in the pathogenesis of autoimmune diseases and cancers. There are no clear criteria to identify Bregs; different markers were used in the different experimental conditions. Massive researches had described the functions of immune cells such as regulatory $\mathrm{T}$ cells (Tregs), dendritic cells (DCs), and B cells in the autoimmune disorder diseases and cancers. More and more researches focused on the roles of Bregs and the cytokines such as Interleukin-10 (IL-10) and transforming growth factor beta (TGF- $\beta$ ) secreted by Bregs. The aim of this review is to summarize the characteristics of Bregs and the roles of Bregs in cancer.
\end{abstract}

\section{Introduction}

The relationship between immune system and cancer development has been well described over the past several decades. The immune system plays an important role in the prevention of tumors. It could specially identify and eliminate tumor cells through the tumor-associated antigens (TAA) or molecules expressed by the tumor cells [1]. This process was described as tumor immune surveillance or tumor immunoediting, which was divided into three essential phases: elimination, equilibrium, and escape. In the first phase, elimination, the transformed cells were recognized and eliminated by the innate immune response such as nature killer cells (NK) and macrophages before they became clinically apparent. The second phase was an equilibrium phase between the tumor cells and immunity. The antigen specific $\mathrm{T}$ cells could induce the adaptive immune response. The tumor cells would decrease the tumor-specific antigens and even lose the major MHCI and MHC-II antigens along with the tumor progression. Finally, in the escape phase, the tumor cells became less immunogenic, escaped from immune attack, and suppressed antitumor immune response leading to the tumor production and growth [2]. Cancer genesis was the result of the immune escape. The immune effector cells and the cytokines played a key role in pursuing each phase. They had been clarified by the roles played in cancer immune surveillance [3]. In recent years, literatures have found some new subsets of the immune cells which are relevant to the tumor immune surveillance and promote the cancer production and progression, for example, the Tregs and Bregs. In this review, we focus on the relationship between the regulatory $\mathrm{B}$ cells and their functions in cancer.

\section{Characteristics of Regulatory B Cells}

2.1. Phenotypes and Markers of Bregs. In recent years, B cells have been demonstrated to downregulate inflammatory reactions and induce tolerance by production of IL-10 and/or TGF- $\beta$ and interacting with pathogenic T cells to inhibit harmful immune responses.

The term "regulatory B cells" was introduced by Mizoguchi and collaborators, who identified Bregs as an IL10 -producing B cell subset in 2002 [4]. Those Bregs had been shown to ameliorate murine allergic and autoimmune diseases, such as contact hypersensitivity (CHS) [5], asthma [6], experimental autoimmune encephalomyelitis (EAE) [7], lupus [8], and collagen induced arthritis (CIA) [9]. Topical studies in CIA had identified the transitional 2 marginal-zone precursor (T2-MZP) cells that played an immunosuppressive function both in vivo and in vitro $[10,11]$. To date, there are no precise unique phenotype markers to identify Bregs. Markers on mouse Bregs resembled those on $\mathrm{CD} 1 \mathrm{~d}^{\text {hi }} \mathrm{CD}^{+} \mathrm{B} 10$ cells 
[5], CD1d ${ }^{\text {hi }}$ MLN B cells $\left(B 220^{+} \mathrm{CD} 1 \mathrm{~d}^{\text {hi }} \mathrm{CD} 21^{\text {int }} \mathrm{CD} 62^{\text {low }}\right.$ IgM $^{\text {int }}$ CD2 $\left.23^{\text {int }}\right)[12]$, CD $1 d^{\text {hi }}$ CD $21^{\text {hi }}$ CD $23^{-}$CD $24^{\text {hi }}$ IgM $^{\text {hi }}$ IgD ${ }^{\text {lo }}$ marginal-zone B cells, $\mathrm{CD} 19^{+} \mathrm{CD} 21^{\text {hi }} \mathrm{CD} 23^{\text {hi }} \mathrm{CD} 24^{\text {hi }}$ IgD $^{\text {hi }}$ IgM $^{\text {hi }}$ CD1d ${ }^{\text {hi }}$ T2-MZP cells [13], and Tim- $1^{+}$Bregs [14]. IL-15 coupled to granulocyte macrophage colony stimulating factor could convent naïve splenic B cells into IL-10producing $B$ cells. Those Bregs shared common markers with B10 cells and T2-MZP Bregs and acquired the expression of CD138 but lost the expression of CD19 [15]. Differing from above regulatory $\mathrm{B}$ cell subsets, the surface characteristics of adipose Bregs were $\mathrm{CD} 1 \mathrm{~d}^{\text {lo }} \mathrm{CD}^{-/ \mathrm{lo}} \mathrm{CD} 11 \mathrm{~b}^{\text {lo }} \mathrm{CD} 21 / \mathrm{CD} 35^{\text {lo }}$ $\mathrm{CD} 23^{-/ 1 \mathrm{lo}} \mathrm{CD} 25^{+} \mathrm{CD} 69^{+} \mathrm{CD}_{2}{ }^{\mathrm{hi}} \mathrm{CD} 185^{-} \mathrm{CD}_{196}{ }^{+} \mathrm{IgM}^{+} \mathrm{IgD}^{+}$ [16]. These Bregs could maintain adipose tissue homeostasis and limit obesity-associated inflammation. The IL-10producing $B$ cell subset characterized in humans normally represents $1 \%$ to $3 \%$ of spleen $B$ cells and $<1 \%$ of peripheral blood B cells [17]. Human regulatory B cells were enriched in both transitional (CD24 $\left.{ }^{\text {hi }} \mathrm{CD} 38^{\text {hi }}\right)$ [18] and memory $\left(\mathrm{CD} 24^{\text {hi }} \mathrm{CD}^{2} 7^{+}\right)$[17] B cells. IL-10 production by CD24 ${ }^{\text {hi }}$ $\mathrm{CD} 27^{+} \mathrm{B}$ cells regulated monocyte tumor necrosis factor alpha (TNF- $\alpha$ ) production [17]. CD $19^{+} \mathrm{CD} 24^{\text {hi }} \mathrm{CD} 38^{\text {hi }} \mathrm{B}$ cells inhibited proinflammatory cytokine production by $\mathrm{CD} 4^{+} \mathrm{T}$ cells, dependent on IL-10, CD80, and CD86 but not TGF$\beta$ [18]. Human $\mathrm{CD} 19^{+} \mathrm{CD} 25^{\text {hi }} \mathrm{CD} 6^{\text {hi }} \mathrm{CD} 1 \mathrm{~d}^{\text {hi }} \mathrm{B}$ regulatory cells could suppress the proliferation of $\mathrm{CD} 4^{+} \mathrm{T}$ cells and enhance Foxp3 and cytotoxic T-lymphocyte antigen 4 (CTLA-4) expression in Treg cells by producing IL-10 and TGF- $\beta$ [19]. Bregs did not belong to any clearly defined B cell subsets but they added value in both the $\mathrm{CD} 27^{+}$and the $\mathrm{CD} 38^{\text {hi }}$ compartments [20]. Regardless of the different markers used to identify Bregs, the majority of protective effects of Bregs are dependent on IL-10 [4, 5, 7, 18, 21], a potent deactivator, which limits the intensity and duration of inflammatory responses. Thus, IL-10 secretion is still a vital standard in the identification of Bregs.

A few of signal pathways were under the responsibility of the production of IL-10 by Bregs. It had been demonstrated that the Breg response could be promoted by stimulation with Toll-like receptor 4 (TLR4) and Toll-like receptor 9 (TLR9) ligands [22]. LPS with PIM (PMA+ionomycin+monensin) could induce B10 cells in vitro [5]. Using a mouse model for multiple sclerosis, B10 cells maturation into functional IL-10-secreting effector cells that inhibited autoimmune diseases in vivo required IL-21 and CD40-dependent cognate interactions with $\mathrm{T}$ cells [23]. IL-21 induced $\mathrm{GrB}^{+}$human Bregs expressing high levels of $\mathrm{GrB}$, which thereby limited $\mathrm{T}$ cell proliferation by a GrB-dependent degradation of the $\mathrm{T}$ cell receptor $\zeta$-chain [24]. Agonistic anti-CD40 specifically targeted T2 B cells and enriched Bregs upon short-term in vitro culture [11]. MyD88 was thought to be involved but not critical to the development of Breg, while played a considerate role in IL-10 expression [20]. B cell linker protein, as a signaling component for Bregs function, was essential for the suppression of CHS and EAE by mediating IL-10 production [25]. Nuclear factor $\kappa \mathrm{B}-\alpha$-kinase $(\mathrm{NF} \kappa \mathrm{B})$ and signal transducer and activator of transcription 3 (STAT3) were involved in the secretion of IL-10 by Bregs [26]. Matsumoto and colleagues had found that the production of IL-10 was reduced in Bregs from mice with stromal interaction molecule 1 (STIM1) and stromal interaction molecule 2 (STIM2) depleted [27].

2.2. The Roles of Bregs in Immune System. Regulatory B cells performed a diversity of mechanisms to regulate immune responses and target many different immune cell types, such as DCs [28] and macrophages [29] as well as T helper 1 (Th1) cells and $\mathrm{T}$ helper 2 (Th2) cells [30]. It has been demonstrated that Bregs were capable of suppressing the proliferation of $\mathrm{CD} 4^{+} \mathrm{CD} 25^{-} \mathrm{T}$ cells [31] and production of interferon gamma (IFN- $\gamma$ ) and IL-17 by Th1 and T helper 17 (Th17) cells, respectively [32,33]. In vitro studies in human had further postulated the potential ability of Breg cells to influence innate immunity by abrogating mitogen-stimulated secretion of TNF- $\alpha$ by monocytes, macrophages, and T cells. Yet regulatory B cells had no impact on the secretion of IL-6 and IL- 8 by CD $4^{+}$T cells [34]. Mean B10 and progenitor B10 cell frequencies from patients with autoimmune disease were significantly higher than controls after CD40L with LPS/CpG stimulation [17]. These suppressive effects were mediated by IL-10. A number of studies indicated that the production of IL-10 by Bregs in mice and human was important for generation of at least two regulatory $\mathrm{T}$ - cell subtypes and conventional Treg cells as well as type 1 regulatory $\mathrm{T}$ cells (Tr1) [32-34]. The lack of Bregs resulted in a decrease of Foxp $^{+}$Tregs [33]. B cell deficiency caused a significant reduction in the number of peripheral but not thymic Tregs. Adoptive transfer of WT B cells into $\mu \mathrm{MT}$ mice restored both Treg numbers and recovery from EAE [35]. B cells isolated from donor MRL/lpr mice and stimulated with agonistic anti-CD40 in vitro converted autologous effector $\mathrm{T}$ cells into Trl cells [11]. Coculture of $\mathrm{CD}^{+} \mathrm{T}$ cells by IL$10^{+} \mathrm{B}$ cells announced that $\mathrm{IL}-10^{+} \mathrm{B}$ cells were in a position to induce $\mathrm{CD} 4^{+} \mathrm{T}$ cells to produce large quantity of IL10 , which mediated the immunosuppression and protection from development of cerebral malaria [31]. IL-10 produced by Bregs was essential for the generation and maintenance of the pool of Tregs. Bregs induced pulmonary infiltration of $\mathrm{CD}^{+} \mathrm{CD}_{25}{ }^{+} \mathrm{Foxp}^{+}{ }^{+}$conventional Tregs, which controlled allergic airway inflammation [13]. As a result, activated Bregs could directly or indirectly target immune cells to regulate immune responses.

\section{Regulatory B Cells in Cancer}

3.1. B Cells in Cancer. Both positive and negative roles of $B$ cells during tumor immunity have been reported. Depletion of CD20-expressing B cells increased tumor burden in the lungs of mice intravenously injected with B16-F10 melanoma [36]. B cells facilitated T-mediated responses, which in turn impaired tumor development $[36,37]$. The induction of $\mathrm{CD} 4^{+}$and $\mathrm{CD}^{+}{ }^{+} \mathrm{T}$ cells was significantly impaired in B celldepleted mice with B16 melanoma tumors [37]. Activated $\mathrm{B}$ cells could mediate significant tumor regression in an IgG2b-dependent manner [36, 38]. These studies highlighted 
the effector function of $B$ cells as a source of IgG $2 b$ which were highly cytotoxic toward tumor cells [38].

Despite these, negative regulatory functions of $\mathrm{B}$ cells during immune responses to tumors have also been proposed. As we know, the mutation and accumulation of B cells and the antibodies secreted by B cells may play decisive roles in the tumor formation. Studies on B cell-deficient $\mu \mathrm{MT}$ mice showed that $\mathrm{B}$ cell deficiency enhanced $\mathrm{CD} 4^{+} \mathrm{T}$ cell priming and helped for $\mathrm{CD} 8^{+} \mathrm{T}$ cell-mediated tumor immunity [39]. The repertoire of $\mathrm{CD} 4^{+}$helper $\mathrm{T}$ cells was limited in the presence of B cells, resulting in reduced antitumor immune responses [40]. Upon stimulation by irradiated tumor cells, the production of IFN- $\gamma$ from $\mathrm{CD} 8^{+} \mathrm{T}$ cells and NK cells was found to be markedly increased in the B cell-deficient as compared with wild-type conditions [41]. Murine EMT6 mammary tumors grew readily in immune competent mice but poorly in B-cell-deficient mice [42]. Syngeneic tumors progressed poorly in $\mu \mathrm{MT}$ mice deficient in B cells unless replenished with B220 $0^{+}$B cells $[40,43]$. B cells could exert lots of functions to promote cancer, such as producing immunoglobulins and cytokines that could induce Fc receptors $(\mathrm{FcR})$ and complement mediated chronic inflammation, whereas the chronic inflammation was required for carcinogenesis [44-46]. B cells produced TGF- $\beta$, thereby mediating suppression of cellular immune responses. Previously, studies showed that B cells required IL-10 and TNF- $\alpha$ to promote tumorigenic. IL-10 and TNF- $\alpha$ probably could mediate Th2 activation and inhibition of cytotoxic activity of $\mathrm{CD}^{+} \mathrm{T}$ cells and nucleus. The cytokines such as TNF- $\alpha$ produced by $\mathrm{B}$ cells could activate the inhibitor of $\kappa \mathrm{B}-\alpha$-kinase ( $\mathrm{I} \kappa \mathrm{B} \alpha$ ), signal transducer, and activator of STAT3 in tumor cells, which would get a relapse of the castration resistant prostate cancer [47]. Moreover, the studies of the tumor growth in a mouse model of skin carcinogenesis had shown that the immune cells infiltrating in the premalignant lesions would reduce in $B$ cell deficiency mice, which resulted in the inhibition of skin carcinoma development. Antibodies secreted by B cells could form the immune complexes (ICs) that would stimulate myeloid cells recruitment at tumor sites, which promoted the tumor growth via binding to the $\mathrm{Fc} \gamma$-activating receptors. Also, the macrophages would become protumor myeloid cells $[44,48]$. A similar role of B cells was observed in a synthetic mammary cancer model. It was reported that the antitumor immune response by $T$ cells was enhanced in mice with $B$ cell deficiency in this cancer model [40]. It also supported that the tumor was reduced by treatment with anti-mouse IgM/IgG antibodies, which would deplete the mutation B cells [49].

3.2. Bregs in Cancer. Bregs, as a separate subpopulation of B cells, have been mainly researched in their roles in the autoimmune diseases and inflammatory diseases [50]. Considering the tumor promoting role of the $\mathrm{B}$ cells and the immune regulating role of the Bregs, recent studies have focused on the role of Bregs in cancer. Previous studies had illustrated that the tumor inhibition effect of $\mathrm{T}$ cells was regulated by IL-10 production, which threw out a point that Bregs might be involved in cancer [41].

Also, IL-10 was a persistent regulatory cytokine which could repress Th1 and Th2 cytokine expression [51]. A recent study showed that Bregs could still secrete antibodies especially with IgM subtype as the activated plasmablast/plasma B cells. Immunoglobulins could also mediate inflammation to promote cancer as described above $[44,52]$.

Prevacid B and coworkers had described a unique subset of Breg cells in the studies with the mouse 4T1 model of breast cancer. The Bregs belonged to the $\mathrm{CD} 19^{+} \mathrm{B} 220^{+}$ $\mathrm{CD} 25^{+}$B2 lymphocytes which were needed in the progress of 4T1 murine breast cancer cells metastasis lung [53]. Since the CD25 is highly expressed on all activated T cells, B cells, and the thymic Tregs, the authors described this novel subpopulation of Bregs as tBregs. This research had found that the proportion of tBregs was significantly increased in peripheral blood and secondary lymphoid organs. 4T1 murine cancer cells could directly induce the generation of tBregs that inhibited the proliferation of nonactive and preactivated T cells. Similar role of tBregs was proved in the human cancers in vitro [54]. tBregs highly expressing TGF- $\beta$ as well as CD40, CD86, and MHC I and II molecules could promote the generation of Foxp $3^{+}$Tregs. The conversion of $\mathrm{CD}^{+} \mathrm{T}$ cells into Tregs was relying on cell contact between $\mathrm{T}$ and $\mathrm{B}$ cells and the TGF- $\beta$ secretion. In the process of lung metastasis of mammary adenocarcinoma 4T1 cancer cells, Tregs were needed in order to inhibit antitumor defenses of NK cells [55]. In conclusion, the researcher had proved that the tBregs could transform nonregulatory $\mathrm{CD} 4^{+}$ $T$ cells (non-Tregs) to active Tregs through secreting the TGF- $\beta$, which in turn inhibited T cells proliferation and increased tumor metastasis $[53,54]$. Also, cancer cells could convert normal B cells into tBregs. So, as long as cancer persists, the cancer cells would induce tBregs generation and inhibit the antitumor immune process $[43,56]$. Recently, it was reported that nonmetastatic cancer cells expressed and utilized metabolites of the 5-lipoxygenase (5-LO) pathway to induce tBregs generation [57]. The presence of inhibitors of 5-LO/FLAP (5-LO activating protein) significantly reduced the expression of almost every tBreg-associated marker, such as decreased expression of CD25, CD81, BAFFR, and B7-H1 and phosphorylation of STAT3. Functionally, these cells also failed to suppress proliferation of $\mathrm{T}$ cells and did not induce conversion of FoxP $3^{+} \mathrm{CD} 4^{+}$Tregs from non-Treg $\mathrm{CD} 4^{+} \mathrm{T}$ cells [57]. This was the first clearly defined example reported on the existence and function of Bregs in cancer.

The anti-CD20 antibody reduction that could deplete B cells was proved to be effective in the treatment of nonHodgkin lymphomas and CLL, but some patients showed resistance to anti-CD20 therapy or eventually relapse. A recent study has revealed that the presence of Bregs and their IL-10 might inhibit the therapy efficacy [58]. B cell depletion by CD20 antibody would greatly enhance cancer progression and metastasis. Both murine and human tBregs expressed low levels of CD20 and, as such, anti-CD20 mostly enriched for these cells [59]. In the study of lymphoma, the model mice received anti-CD20 treatment and then, following transfer of Bregs, resulted in tumor burden significantly increased $[58,60]$. Bregs could affect the phagocytic capacity of macrophages, both in vivo and in vitro [58]. Myeloid cells and macrophages were responsible for clearance of antiCD20 bound to tumor cells [60]. 
TABLE 1: The immunophenotype and naming of the regulatory B cells in mouse and human.

\begin{tabular}{|c|c|c|c|}
\hline Species & Marker/phenotype & Naming & References \\
\hline \multirow{4}{*}{ Human } & $\mathrm{CD} 24^{\mathrm{hi}} \mathrm{CD} 27^{+}$ & B10 cells & {$[17]$} \\
\hline & $\mathrm{CD} 19^{+} \mathrm{CD} 25^{\mathrm{hi}} \mathrm{CD} 86^{\mathrm{hi}} \mathrm{CD} 1 \mathrm{~d}^{\mathrm{hi}}$ & Bregs & {$[19]$} \\
\hline & $\mathrm{CD} 19^{+} \mathrm{CD} 24^{\mathrm{hi}} \mathrm{CD} 38^{\mathrm{hi}}$ & Bregs & {$[18]$} \\
\hline & $\mathrm{CD}_{1}{ }^{+} \mathrm{CD}_{3} 8^{+} \mathrm{CD}_{1}{ }^{+} \mathrm{IgM}^{+} \mathrm{CD}_{147^{+}} \mathrm{GrB}^{+}$ & $\mathrm{GrB}^{+}$Bregs & {$[24]$} \\
\hline \multirow{7}{*}{ Mouse } & $\mathrm{CD} 19^{+} \mathrm{CD}^{+} \mathrm{CD}^{\mathrm{hi}} \mathrm{d}^{\mathrm{hi}}$ & B10 cells & {$[5]$} \\
\hline & $\mathrm{B} 220^{+} \mathrm{CD} 21^{\text {int }} \mathrm{CD} 62^{\text {int }} \operatorname{IgM}^{\text {int }} \mathrm{CD} 23^{\text {hi }} \mathrm{CD} 1 \mathrm{~d}^{\text {hi }}$ & CD1d ${ }^{\text {hi }}$ MLN B cells & {$[12]$} \\
\hline & $\mathrm{CD} 1 \mathrm{~d}^{\text {hi }} \mathrm{CD} 21^{\text {hi }} \mathrm{CD} 23^{-} \mathrm{CD} 24^{\text {hi }} \operatorname{IgM}^{\text {hi }} \operatorname{IgD}^{\text {lo }}$ & Marginal zone B cells & {$[13]$} \\
\hline & $\mathrm{CD} 19^{+} \mathrm{CD} 21^{\text {hi }} \mathrm{CD} 23^{\text {hi }} \mathrm{CD} 24^{\text {hi }} \operatorname{IgD}^{\text {hi }} \operatorname{IgM}^{\text {hi }} \mathrm{CD} 1 d^{\text {hi }}$ & $\begin{array}{l}\text { Transitional } 2 \text { marginal-zone precursor } \\
\text { (T2-MZP) }\end{array}$ & {$[13]$} \\
\hline & Tim- $1^{+}$ & Tim $-1^{+}$Bregs & [14] \\
\hline & 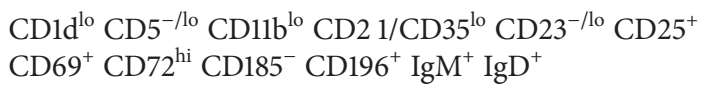 & Adipose IL- $10^{+} \mathrm{B}$ cells & [16] \\
\hline & $\mathrm{CD} 19^{+} \mathrm{B} 220^{+} \mathrm{CD} 25^{+}$ & Tumor-evoked regulatory B cells (tBregs) & {$[53]$} \\
\hline
\end{tabular}

In the study of 7,12-dimethylbenzanthracene (DMBA) and 12-O-tetradecanoylphorbol-13-acetate (TPA) induced skin carcinogenesis, the cancer growth was reduced in B cell deficiency mice (Rag2 $2^{-/-}$mice) [61]. However, it would be partially rescued with transfer of B cells. Nonetheless, transfer of $B$ cells could not promote the skin cancers in Rag2 ${ }^{-/-}$mice when the mice were deficient of TNF- $\alpha$. TNF- $\alpha$ knockout mice transferred of B cells could not enhance the skin cancer either. The number of $\mathrm{CD} 19^{+} \mathrm{CD} 21^{+} \mathrm{IL}-10$-secreting B cells which were defined as Bregs showed significant decrease in TNF- $\alpha$ KO mice. The results above suggested that Bregs could promote cancer growth and the secretion of TNF- $\alpha$ might lead to the generation and accumulation of Bregs in cancer.

Recently, study found that IL-21 induced GrB-expressing Breg cells resided within the microenvironment of different tumor types including breast, ovarian, cervical, colorectal, and prostate carcinomas [24]. $\mathrm{GrB}^{+} \mathrm{B}$ cells might contribute to the modulation of cellular adaptive immune responses by Treg-like mechanisms, possibly allowing the escape of certain tumors from an efficient antitumor immune response [24].

\section{Conclusion}

Both cancer escape and autoimmune diseases belonged to the inappropriate regulatory immune process. B cells mediated humoral immunity by secreting antibody and also regulated $\mathrm{T}$ cell maturation and function via serving as APCs and providing regulatory molecules [62]. The functions of B cells in autoimmunity and cancer diseases were well described. Lots of evidences had suggested the promoting tumor role of $\mathrm{B}$ cells, probably through inhibiting the activation of $\mathrm{T}$ cells, especially the $\mathrm{CD}^{+} \mathrm{T}$ cells. In recent years, a distinct subpopulation of $\mathrm{B}$ cells that performed significant immunosuppressive has been described. Despite the fact that more and more literatures focused on the regulatory B cells, their clear phenotype and characteristic markers are still not definite. Since all the Bregs could secrete IL-10 and the majority of protective effects of Bregs required IL-10, IL-10 secreting B cells was considered as Bregs. The phenotype and naming of human and mouse Bregs in different experimental conditions were displayed in Table 1.

Bregs, as a subset of B cells, could exert B cells function such as secreting antibody and cytokines, which induced the IC production and stimulated cell signal resulting in tumor progression. Bregs as well as total B cells could promote cancer growth mainly by inhibiting the cytotoxic activity of Th1/CD8+ cells. This process was actually mediated by their IL-10 and TGF- $\beta$ production.

As we discussed above in all mouse cancer models, Bregs, together with other components of immune system, promoted tumor progression. IL-10 produced by Bregs could reduce the Th1/CD8 ${ }^{+}$cells. Furthermore, TGF- $\beta$ secreted by Bregs could convert $\mathrm{CD} 4^{+} \mathrm{T}$ cells into Tregs that would promote tumor progression. In studies of anticancer therapies by anti-CD20 therapy, Bregs and their IL-10 should be responsible for the development of lymphoma resistance to anti-CD20 therapy.

There are still some subjects of Bregs that remain to be established. Whether Bregs can affect other immune cells and whether different subset of Bregs can differentially participate in immune modulation have not been illustrated. Also, further studies are needed to research on tumor treatment through targeting Bregs.

\section{Conflict of Interests}

The authors declare that there is no conflict of interests regarding the publication of this paper.

\section{Authors' Contribution}

Yan He and Hongyan Qian contributed equally to this work. 


\section{Acknowledgments}

This study was supported by the National Basic Research Program of China (973 Program) (no. 2014CB541903) and the National Nature Science Foundation of China (nos. 81273285, 81302565, and 81302564).

\section{References}

[1] M. L. Disis, "Immune regulation of cancer," Journal of Clinical Oncology, vol. 28, no. 29, pp. 4531-4538, 2010.

[2] J. B. Swann and M. J. Smyth, "Immune surveillance of tumors," Journal of Clinical Investigation, vol. 117, no. 5, pp. 1137-1146, 2007.

[3] R. Kim, M. Emi, and K. Tanabe, "Cancer immunoediting from immune surveillance to immune escape," Immunology, vol. 121, no. 1, pp. 1-14, 2007.

[4] A. Mizoguchi, E. Mizoguchi, H. Takedatsu, R. S. Blumberg, and A. K. Bhan, "Chronic intestinal inflammatory condition generates IL-10-producing regulatory B cell subset characterized by CD1d upregulation," Immunity, vol. 16, no. 2, pp. 219-230, 2002.

[5] K. Yanaba, J.-D. Bouaziz, K. M. Haas, J. C. Poe, M. Fujimoto, and T. F. Tedder, "A regulatory $B$ cell subset with a unique $\mathrm{CD} \mathrm{d}^{h i} \mathrm{CD}^{+}$phenotype controls $\mathrm{T}$ cell-dependent inflammatory responses," Immunity, vol. 28, no. 5, pp. 639-650, 2008.

[6] S. Amu, S. P. Saunders, M. Kronenberg, N. E. Mangan, A. Atzberger, and P. G. Fallon, "Regulatory B cells prevent and reverse allergic airway inflammation via FoxP3-positive $\mathrm{T}$ regulatory cells in a murine model," Journal of Allergy and Clinical Immunology, vol. 125, no. 5, pp. 1114.e8-1124.e8, 2010.

[7] T. Matsushita, K. Yanaba, J.-D. Bouaziz, M. Fujimoto, and T. F. Tedder, "Regulatory B cells inhibit EAE initiation in mice while other B cells promote disease progression," Journal of Clinical Investigation, vol. 118, no. 10, pp. 3420-3430, 2008.

[8] R. Watanabe, N. Ishiura, H. Nakashima et al., "Regulatory B cells (B10 cells) have a suppressive role in murine lupus: CD19 and B10 cell deficiency exacerbates systemic autoimmunity," Journal of Immunology, vol. 184, no. 9, pp. 4801-4809, 2010.

[9] S. Fillatreau, C. H. Sweenie, M. J. McGeachy, D. Gray, and S. M. Anderton, "B cells regulate autoimmunity by provision of IL10," Nature Immunology, vol. 3, no. 10, pp. 944-950, 2002.

[10] J. G. Evans, K. A. Chavez-Rueda, A. Eddaoudi et al., "Novel suppressive function of transitional $2 \mathrm{~B}$ cells in experimental arthritis," Journal of Immunology, vol. 178, no. 12, pp. 7868-7878, 2007.

[11] P. A. Blair, K. A. Chavez-Rueda, J. G. Evans et al., "Selective targeting of B cells with agonistic anti-CD40 is an efficacious strategy for the generation of induced regulatory T2-like B cells and for the suppression of lupus in MRL/lpr mice," Journal of Immunology, vol. 182, no. 6, pp. 3492-3502, 2009.

[12] V. Di Caro, B. Phillips, C. Engman et al., "Involvement of suppressive B-lymphocytes in the mechanism of tolerogenic dendritic cell reversal of type 1 diabetes in NOD mice," PLoS ONE, vol. 9, no. 1, Article ID e83575, 2014.

[13] C. Mauri and A. Bosma, "Immune regulatory function of B cells," Annual Review of Immunology, vol. 30, pp. 221-241, 2012.

[14] Q. Ding, M. Yeung, G. Camirand et al., "Regulatory B cells are identified by expression of TIM-1 and can be induced through TIM-1 ligation to promote tolerance in mice," Journal of Clinical Investigation, vol. 121, no. 9, pp. 3645-3656, 2011.
[15] M. Rafei, J. Hsieh, S. Zehntner et al., "A granulocytemacrophage colony-stimulating factor and interleukin-15 fusokine induces a regulatory B cell population with immune suppressive properties," Nature Medicine, vol. 15, no. 9, pp. 1038-1045, 2009.

[16] S. Nishimura, I. Manabe, S. Takaki et al., "Adipose natural regulatory B cells negatively control adipose tissue inflammation," Cell Metabolism, vol. 18, no. 5, pp. 759-766, 2013.

[17] Y. Iwata, T. Matsushita, M. Horikawa et al., "Characterization of a rare IL-10-competent B-cell subset in humans that parallels mouse regulatory B10 cells," Blood, vol. 117, no. 2, pp. 530-541, 2011.

[18] P. A. Blair, L. Y. Noreña, F. Flores-Borja et al., "CD $19^{+} \mathrm{CD} 24^{h i} \mathrm{CD} 38^{h i}$ B cells exhibit regulatory capacity in healthy individuals but are functionally impaired in systemic lupus erythematosus patients," Immunity, vol. 32, no. 1, pp. 129-140, 2010.

[19] A. Kessel, T. Haj, R. Peri et al., "Human $\mathrm{CD} 19^{+} \mathrm{CD} 25^{\text {high }} \mathrm{B}$ regulatory cells suppress proliferation of $\mathrm{CD}^{+} \mathrm{T}$ cells and enhance Foxp3 and CTLA-4 expression in T-regulatory cells," Autoimmunity Reviews, vol. 11, no. 9, pp. 670-677, 2012.

[20] I. Kalampokis, A. Yoshizaki, and T. F. Tedder, "IL-10-producing regulatory B cells (B10 cells) in autoimmune disease," Arthritis Research and Therapy, vol. 15, no. 1, article S1, 2013.

[21] S. N. Byrne and G. M. Halliday, "B cells activated in lymph nodes in response to ultraviolet irradiation or by interleukin-10 inhibit dendritic cell induction of immunity," Journal of Investigative Dermatology, vol. 124, no. 3, pp. 570-578, 2005.

[22] K. Miles, J. Heaney, Z. Sibinska et al., "A tolerogenic role for Toll-like receptor 9 is revealed by B-cell interaction with DNA complexes expressed on apoptotic cells," Proceedings of the National Academy of Sciences of the United States of America, vol. 109, no. 3, pp. 887-892, 2012.

[23] A. Yoshizaki, T. Miyagaki, D. J. Dilillo et al., "Regulatory B cells control T-cell autoimmunity through IL-21-dependent cognate interactions," Nature, vol. 491, no. 7423, pp. 264-268, 2012.

[24] S. Lindner, K. Dahlke, K. Sontheimer et al., "Interleukin 21induced granzyme b-expressing b cells infiltrate tumors and regulate t cells," Cancer Research, vol. 73, no. 8, pp. 2468-2479, 2013.

[25] G. Jin, Y. Hamaguchi, T. Matsushita et al., "B-cell linker protein expression contributes to controlling allergic and autoimmune diseases by mediating IL-10 production in regulatory B cells," Journal of Allergy and Clinical Immunology, vol. 131, no. 6, pp. 1674.e9-1682.e9, 2013.

[26] X. Yang, J. Yang, Y. Chu et al., “T follicular helper cells mediate expansion of regulatory B cells via IL-21 in LupusProne MRL/lpr mice," PLoS ONE, vol. 8, no. 4, Article ID e62855, 2013.

[27] M. Matsumoto, Y. Fujii, A. Baba, M. Hikida, T. Kurosaki, and Y. Baba, "The calcium sensors STIM1 and STIM2 control B cell regulatory function through interleukin-10 production," Immunity, vol. 34, no. 5, pp. 703-714, 2011.

[28] T. Matsushita, M. Horikawa, Y. Iwata, and T. F. Tedder, "Regulatory B cells (B10 cells) and regulatory T cells have independent roles in controlling experimental autoimmune encephalomyelitis initiation and late-phase immunopathogenesis," Journal of Immunology, vol. 185, no. 4, pp. 2240-2252, 2010.

[29] S.-C. Wong, A.-L. Puaux, M. Chittezhath et al., "Macrophage polarization to a unique phenotype driven by B cells," European Journal of Immunology, vol. 40, no. 8, pp. 2296-2307, 2010. 
[30] J. Tian, D. Zekzer, L. Hanssen, Y. Lu, A. Olcott, and D. L. Kaufman, "Lipopolysaccharide-activated B cells down-regulate Th1 immunity and prevent autoimmune diabetes in nonobese diabetic mice," Journal of Immunology, vol. 167, no. 2, pp. 10811089, 2001.

[31] Y. Liu, Y. Chen, Z. Li et al., "Role of IL-10-producing regulatory $\mathrm{B}$ cells in control of cerebral malaria in Plasmodium berghei infected mice," European Journal of Immunology, vol. 43, no. 11, pp. 2907-2918, 2013.

[32] N. A. Carter, E. C. Rosser, and C. Mauri, "Interleukin-10 produced by B cells is crucial for the suppression of Th17/Th1 responses, induction of $\mathrm{T}$ regulatory type 1 cells and reduction of collagen-induced arthritis," Arthritis Research and Therapy, vol. 14, no. 1, article R32, 2012.

[33] N. A. Carter, R. Vasconcellos, E. C. Rosser et al., "Mice lacking endogenous IL-10-producing regulatory B cells develop exacerbated disease and present with an increased frequency of Th1/Th17 but a decrease in regulatory T cells," Journal of Immunology, vol. 186, no. 10, pp. 5569-5579, 2011.

[34] F. Flores-Borja, A. Bosma, D. Ng et al., "CD19 ${ }^{+} \mathrm{CD} 24^{h i} \mathrm{CD} 38^{h i} \mathrm{~B}$ cells maintain regulatory $\mathrm{T}$ cells while limiting $\mathrm{TH} 1$ and $\mathrm{TH} 17$ differentiation," Science Translational Medicine, vol. 5, no. 173, Article ID 173ra23, 2013.

[35] A. Ray, S. Basu, C. B. Williams, N. H. Salzman, and B. N. Dittel, "A novel IL-10-independent regulatory role for B cells in suppressing autoimmunity by maintenance of regulatory $\mathrm{T}$ cells via GITR ligand," Journal of Immunology, vol. 188, no. 7, pp. 3188-3198, 2012.

[36] R. Sorrentino, S. Morello, G. Forte et al., "B cells contribute to the antitumor activity of $\mathrm{CpG}$-oligodeoxynucleotide in a mouse model of metastatic lung carcinoma," The American Journal of Respiratory and Critical Care Medicine, vol. 183, no. 10, pp.13691379, 2011.

[37] D. J. DiLillo, K. Yanaba, and T. F. Tedder, "B cells are required for optimal $\mathrm{CD}^{+}$and $\mathrm{CD} 8^{+} \mathrm{T}$ cell tumor immunity: therapeutic B cell depletion enhances B16 melanoma growth in mice," Journal of Immunology, vol. 184, no. 7, pp. 4006-4016, 2010.

[38] Q. Li, S. Teitz-Tennenbaum, E. J. Donald, M. Li, and A. E. Chang, "In vivo sensitized and in vitro activated B cells mediate tumor regression in cancer adoptive immunotherapy," Journal of Immunology, vol. 183, no. 5, pp. 3195-3203, 2009.

[39] S. Shah, A. A. Divekar, S. P. Hilchey et al., "Increased rejection of primary tumors in mice lacking B cells: inhibition of anti-tumor CTL and TH1 cytokine responses by B cells," International Journal of Cancer, vol. 117, no. 4, pp. 574-586, 2005.

[40] Z. Qin, G. Richter, T. Schüler, S. Ibe, X. Cao, and T. Blankenstein, "B cells inhibit induction of T cell-dependent tumor immunity," Nature Medicine, vol. 4, no. 5, pp. 627-630, 1998.

[41] S. Inoue, W. W. Leitner, B. Golding, and D. Scott, "Inhibitory effects of B cells on antitumor immunity," Cancer Research, vol. 66, no. 15, pp. 7741-7747, 2006.

[42] Y. Zhang, Y. Eliav, S.-U. Shin et al., "B lymphocyte inhibition of anti-tumor response depends on expansion of Treg but is independent of B-cell IL-10 secretion," Cancer Immunology, Immunotherapy, vol. 62, no. 1, pp. 87-99, 2013.

[43] P. B. Olkhanud, D. Baatar, M. Bodogai et al., "Breast cancer lung metastasis requires expression of chemokine receptor CCR4 and regulatory T cells," Cancer Research, vol. 69, no. 14, pp. 5996-6004, 2009.

[44] K. E. De Visser, L. V. Korets, and L. M. Coussens, "De novo carcinogenesis promoted by chronic inflammation is $\mathrm{B}$ lymphocyte dependent," Cancer Cell, vol. 7, no. 5, pp. 411-423, 2005.

[45] A. N. Houghton, H. Uchi, and J. D. Wolchok, "The role of the immune system in early epithelial carcinogenesis: B-ware the double-edged sword," Cancer Cell, vol. 7, no. 5, pp. 403-405, 2005.

[46] H. Schreiber, T. H. Wu, J. Nachman, and D. A. Rowley, "Immunological enhancement of primary tumor development and its prevention," Seminars in Cancer Biology, vol. 10, no. 5, pp. 351-357, 2000.

[47] M. Ammirante, J.-L. Luo, S. Grivennikov, S. Nedospasov, and M. Karin, "B-cell-derived lymphotoxin promotes castrationresistant prostate cancer," Nature, vol. 464, no. 7286, pp. 302305, 2010.

[48] P. Andreu, M. Johansson, N. I. Affara et al., "FcR $\gamma$ Activation regulates inflammation-associated squamous carcinogenesis," Cancer Cell, vol. 17, no. 2, pp. 121-134, 2010.

[49] E. Barbera-Guillem, M. B. Nelson, B. Barr et al., "B lymphocyte pathology in human colorectal cancer. Experimental and clinical therapeutic effects of partial B cell depletion," Cancer Immunology Immunotherapy, vol. 48, no. 10, pp. 541-549, 2000.

[50] J.-M. Berthelot, C. Jamin, K. Amrouche, B. Le Goff, Y. Maugars, and P. Youinou, "Regulatory B cells play a key role in immune system balance," Joint Bone Spine, vol. 80, no. 1, pp. 18-22, 2013.

[51] D. F. Fiorentino, A. Zlotnik, T. R. Mosmann, M. Howard, and A. O'Garra, "IL-10 inhibits cytokine production by activated macrophages," Journal of Immunology, vol. 147, no. 11, pp. 38153822, 1991.

[52] M. J. Townsend, J. G. Monroe, and A. C. Chan, "B-cell targeted therapies in human autoimmune diseases: an updated perspective," Immunological Reviews, vol. 237, no. 1, pp. 264283, 2010.

[53] P. B. Olkhanud, B. Damdinsuren, M. Bodogai et al., "Tumorevoked regulatory B cells promote breast cancer metastasis by converting resting $\mathrm{CD}^{+}{ }^{+} \mathrm{T}$ cells to T-regulatory cells," Cancer Research, vol. 71, no. 10, pp. 3505-3515, 2011.

[54] P. B. Olkhanud, Y. Rochman, M. Bodogai et al., "Thymic stromal lymphopoietin is a key mediator of breast cancer progression," Journal of Immunology, vol. 186, no. 10, pp. 5656-5662, 2011.

[55] M. Lelekakis, J. M. Moseley, T. J. Martin et al., "A novel orthotopic model of breast cancer metastasis to bone," Clinical and Experimental Metastasis, vol. 17, no. 2, pp. 163-170, 1999.

[56] G. Z. Song, J. Wang, P. Wang, J. D. Gray, and D. A. Horwitz, "IL-2 is essential for TGF- $\beta$ to convert naive CD $4{ }^{+} \mathrm{CD} 25$ - cells to $\mathrm{CD} 25^{+}$Foxp $3^{+}$regulatory $\mathrm{T}$ cells and for expansion of these cells," Journal of Immunology, vol. 178, no. 4, pp. 2018-2027, 2007.

[57] K. Wejksza, L.-C. Catalina, M. Bodogai et al., "Cancer-produced metabolites of 5-lipoxygenase induce tumor-evoked regulatory B Cells via peroxisome proliferator-activated receptor $\alpha$," Journal of Immunology, vol. 190, no. 6, pp. 2575-2584, 2013.

[58] M. Horikawa, V. Minard-Colin, T. Matsushita, and T. F. Tedder, "Regulatory B cell production of IL-10 inhibits lymphoma depletion during CD20 immunotherapy in mice," Journal of Clinical Investigation, vol. 121, no. 11, pp. 4268-4280, 2011.

[59] M. Bodogai, C. L. Chang, K. Wejksza et al., "Anti-CD20 antibody promotes cancer escape via enrichment of tumorevoked regulatory B cells expressing low levels of CD20 and CD137L," Cancer Research, vol. 73, no. 7, pp. 2127-2138, 2013.

[60] V. Minard-Colin, Y. Xiu, J. C. Poe et al., "Lymphoma depletion during CD20 immunotherapy in mice is mediated by macrophage FcgammaRI, FcgammaRIII, and FcgammaRIV," Blood, vol. 112, no. 4, pp. 1205-1213, 2008. 
[61] T. Schioppa, R. Moore, R. G. Thompson et al., "B regulatory cells and the tumor-promoting actions of TNF- $\alpha$ during squamous carcinogenesis," Proceedings of the National Academy of Sciences of the United States of America, vol. 108, no. 26, pp. 10662-10667, 2011.

[62] T. W. Lebien and T. F. Tedder, "B lymphocytes: how they develop and function," Blood, vol. 112, no. 5, pp. 1570-1580, 2008. 


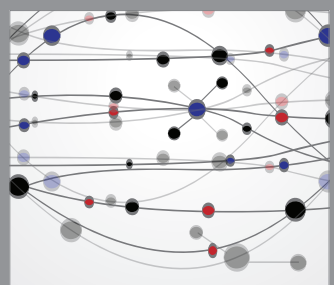

The Scientific World Journal
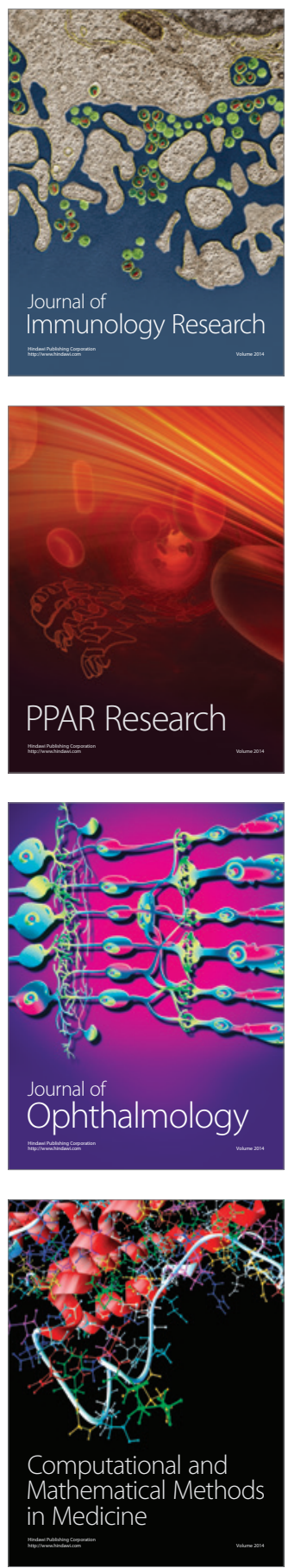

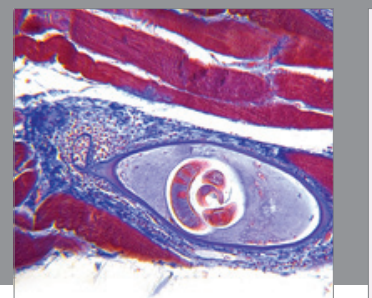

Gastroenterology

Research and Practice
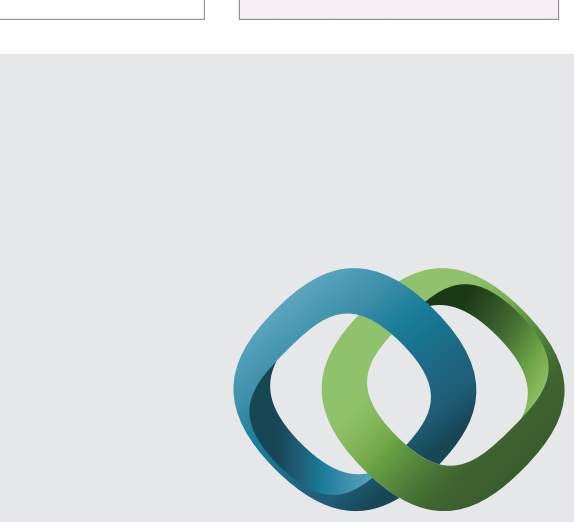

\section{Hindawi}

Submit your manuscripts at

http://www.hindawi.com
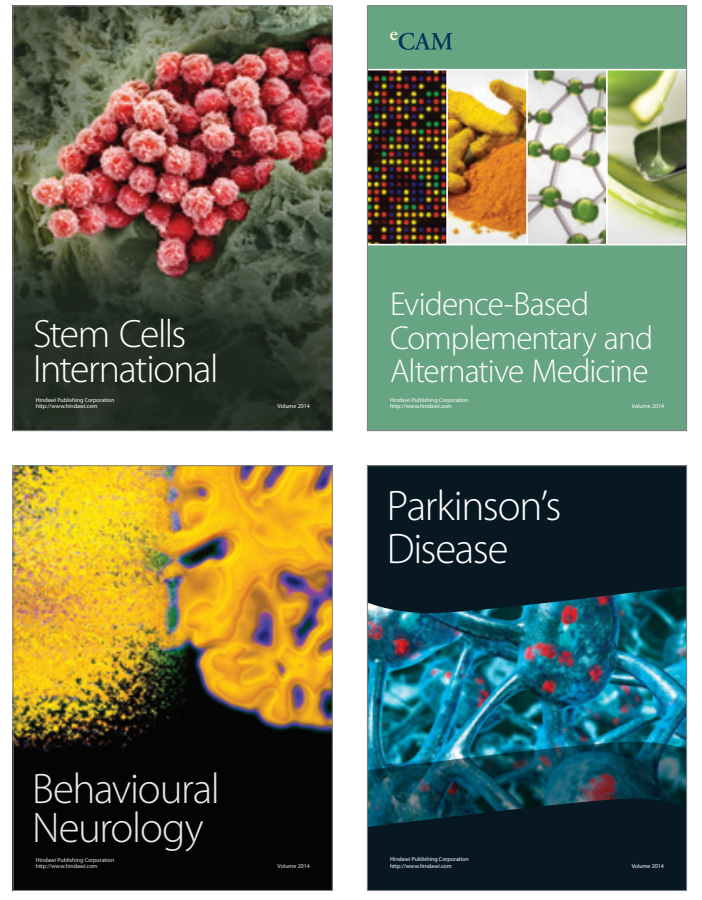
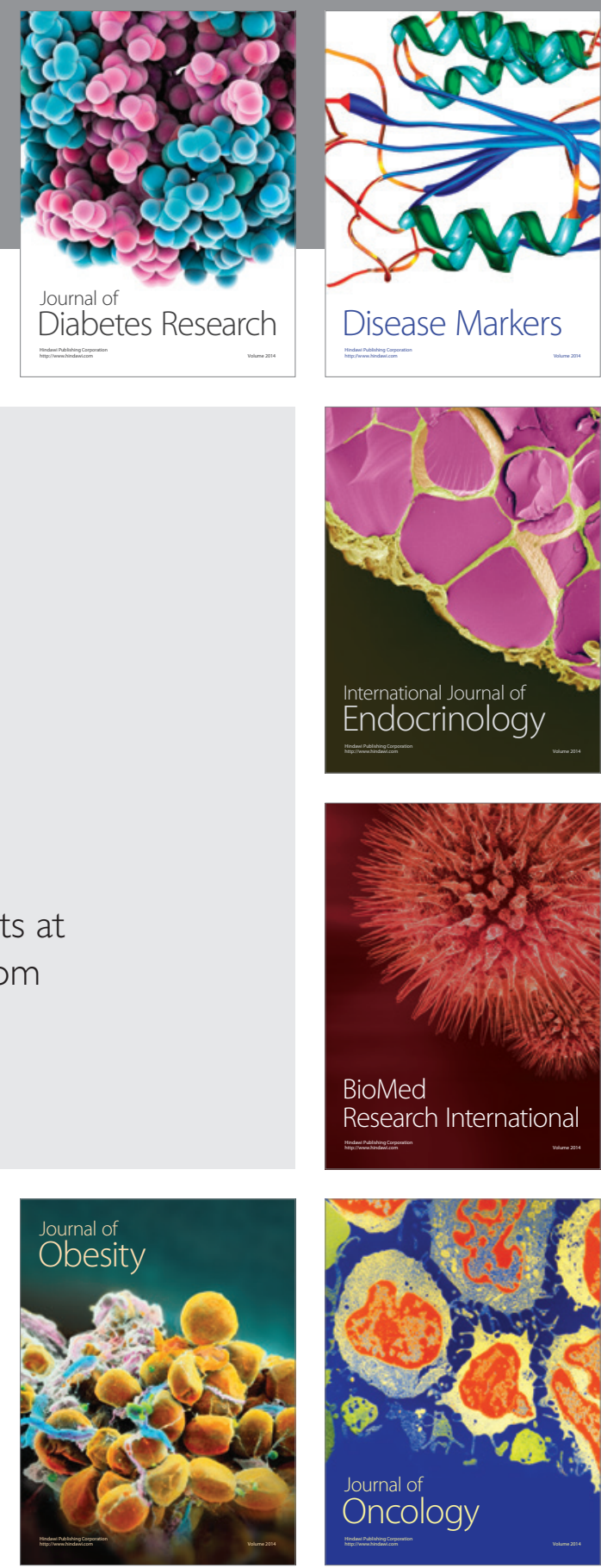

Disease Markers
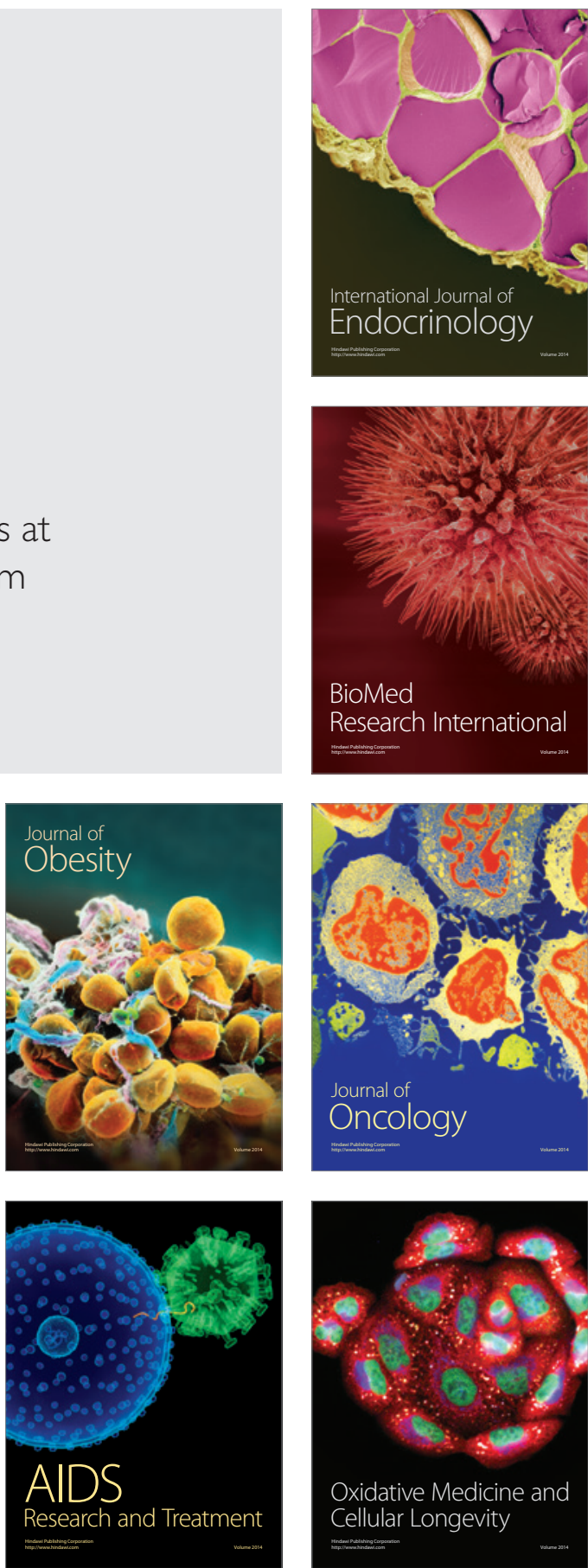